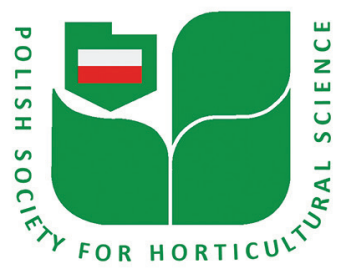

Folia Hort. 33(2) (2021): 354-364

\title{
Evaluation of postharvest storability of Ponkan mandarins stored at different temperatures
}

\author{
Nan Cai ${ }^{1}$, Chunpeng Wan $^{1}$, Jinyin Chen ${ }^{1,2, *}$, Chuying Chen ${ }^{1, *}$ \\ ${ }^{1}$ Jiangxi Key Laboratory for Postharvest Technology and Nondestructive Testing of Fruits and Vegetables / Collaborative \\ Innovation Center of Postharvest Key Technology and Quality Safety of Fruits and Vegetables in Jiangxi Province, Jiangxi \\ Agricultural University, Nanchang 330045, Jiangxi Province, PR China \\ ${ }^{2}$ College of Materials and Chemical Engineering, Pingxiang University, Pingxiang 337055, Jiangxi Province, PR China
}

\begin{abstract}
The effects of storage temperature on postharvest storability, quality attributes and antioxidant enzyme activities of harvested Ponkan mandarins were investigated. Fresh fruits were randomly divided into four groups and stored at different temperatures $\left[5 \pm 1{ }^{\circ} \mathrm{C}(\mathrm{S} 5), 10 \pm 1{ }^{\circ} \mathrm{C}(\mathrm{S} 10), 15 \pm 1{ }^{\circ} \mathrm{C}(\mathrm{S} 15)\right.$, and $20 \pm 1{ }^{\circ} \mathrm{C}(\mathrm{S} 20$ or control)] for 120 days. The results indicated that, compared with the control fruit, low-temperature storage at $10^{\circ} \mathrm{C}$ significantly delayed the increase in fruit decay rate, weight loss, citrus colour index, respiration intensity, relative electrical conductivity, the accumulation of hydrogen peroxide and malondialdehyde, retarded the decline in $\mathrm{L}^{*}$ value, retained high contents of total soluble solid, titratable acid, vitamin C, total phenol and total flavonoid, as well as higher activities of antioxidant enzymes - superoxide dismutase, catalase, peroxidase and ascorbic peroxidase. The principal component analysis results showed that lowtemperature storage significantly maintained the postharvest quality of Ponkan mandarins, with fruit stored at $10^{\circ} \mathrm{C}$ having no significant difference from the fruit stored at $5{ }^{\circ} \mathrm{C}$, but markedly higher than those fruit stored at $15{ }^{\circ} \mathrm{C}$. The comprehensive result of single-factor analysis and PCA showed that $10{ }^{\circ} \mathrm{C}$ could be used as the optimum storage temperature for improving the postharvest storability of Ponkan mandarins.
\end{abstract}

KEYWORDS: antioxidant enzymes, Citrus reticulata Blanco, fruit senescence, principal component analysis, storability

ABBREVIATIONS: APX, ascorbic peroxidase; CAT, catalase; CCI, citrus colour index; $\mathrm{H}_{2} \mathrm{O}_{2}$, hydrogen peroxide; MDA, malondialdehyde; PCA, principal component analysis; POD, peroxidase; RI, respiration intensity; SOD, superoxide dismutase; TA, titratable acid; TFC, total flavonoid content; TPC, total phenol content; TSS, total soluble solid; VC, vitamin $\mathrm{C}$.

\section{INTRODUCTION}

Ponkan mandarins (Citrus reticulata Blanco, PM) are one of the main loose-skin citrus cultivars and are widely cultivated in Southern China. Jing'an Ponkan mandarin is a famous mandarin variety in Jiangxi Province, characterised by a compact plant type, early fruit bearing, rounded fruit shape, bright colour, sweet taste, crisp flesh, high storability, and late maturity (Tang et al., 2017; Gao et al., 2018). These mandarins are a major source of economic income for fruit growers in the Jing'an area.

Appropriate postharvest treatment can significantly reduce fruit loss, improve fruit quality, and result in higher profits. However, citrus fruit may exhibit various disorders during harvest that limit the storage period and reduce their commercial value (Henriod et al., 2005; Undurraga et al., 2009; Chaudhary et al., 2017).

*Corresponding author.

e-mail: cy.chen@jxau.edu.cn (Chuying Chen), jinyinchen@126.com (Jinyin Chen). 
Cold storage is the most frequently used preservation technology to maintain postharvest quality and extend the storage life of fresh citrus fruits, such as grapefruits, mandarins, tangerines and lemons (Montero et al., 2009; Undurraga et al., 2009; Chaudhary etal., 2017; Matsumoto et al., 2019). The recommended storage temperatures (RST) for postharvest citrus fruit range from $5{ }^{\circ} \mathrm{C}$ to $8{ }^{\circ} \mathrm{C}$ (Tietel et al., 2012). However, Ponkan mandarins are highly susceptible to the damage of chilling injury (CI) in the peel when stored at the RST condition (Zhu et al., 2011). The most obvious symptom of CI is peel browning spots, which directly affect consumer perception and reduce the postharvest storability of Ponkan mandarins. Matsumoto et al. (2009) reported that the carotenoid content in Satsuma mandarin (Citrus unshiu Marc.) fruit stored at $20^{\circ} \mathrm{C}$ was higher than that in fruit stored at $5{ }^{\circ} \mathrm{C}$ and $30^{\circ} \mathrm{C}$. Thus, the appropriate storage temperatures are extremely important to reduce postharvest loss and enhance the storability of Ponkan mandarins.

Storage temperature affects the citrus peel colour, fruit respiration and fruit physiological metabolism of organic acid, sugar, vitamin C (VC), etc (Cronje et al., 2011; Tietel et al., 2012; Bal, 2013). During storage, appropriate temperature can reduce the occurrence of pests and diseases (Ning et al., 2019); delay postharvest rind breakdown (Cronje et al., 2011); decrease the fruit rot rate (Wang et al., 2018); maintain the lustre and flavour of the fruit (Tietel et al., 2012); maintain high total soluble solids (TSS) and titratable acid (TA) contents (Ding et al., 1998); maintain antioxidant enzyme activities, such as superoxide dismutase (SOD), peroxidase (POD), catalase (CAT) and ascorbate peroxidase (APX) activities, and enhance antioxidant capacity (Undurraga et al., 2009; Rao et al., 2011). Postharvest fruit senescence is accompanied by the accumulation of malondialdehyde (MDA) content, accelerating the progress of membrane lipid peroxidation and poisoning cell organelles (Zhang et al., 2011; Chen et al., 2019). A too high or too low storage temperature is harmful to fruits. Therefore, determining the suitable storage temperature for Ponkan mandarins after harvest is crucial. Studies have reported that long-term storage of mandarin fruits at room temperatures of $15{ }^{\circ} \mathrm{C}$ leads to a decrease in the flavour quality of the mandarins and the accumulation of spoiled flavours (Sala, 1998; Carvajal et al., 2011). Compared with grapefruit stored at higher $\left(12{ }^{\circ} \mathrm{C}\right)$ or lower $\left(4^{\circ} \mathrm{C}\right)$ temperatures, longterm storage at an intermediate temperature of $8^{\circ} \mathrm{C}$ can better maintain their flavour (Schirra, 1993). Therefore, the minimum safe temperature for postharvest storage of citrus is suggested to be between $5{ }^{\circ} \mathrm{C}$ and $8{ }^{\circ} \mathrm{C}$ (Tietel et al., 2012). The susceptibility of citrus fruits to CI varies with cultivars, such as mandarin, sweet orange, pummelo, grapefruit and lemon. When stored in the range of $2{ }^{\circ} \mathrm{C}$ to $6^{\circ} \mathrm{C}$, CI may occur in grapefruit, Shamouti orange, Vorschach orange and lemon fruit (Chalutz et al., 1985). Sala (1998) also found that CI reduced the appearance quality and commercial value of citrus fruit. Based on the above, the proper storage temperature of Ponkan mandarins acts an important role in the decrease of postharvest loss, maintenance of better nutritional quality and extension of fruit storagelife after harvest.

The suitable storage conditions of fruit cannot be reflected by a single index, but requires a comprehensive analysis ofmultiple indexes. Principal componentanalysis (PCA) is an analysis method that transforms multiple variables into multiple comprehensive variables (Kan et al., 2019; Nie et al., 2020). Then, the correlation between different variables is explained by Pearson correlation analysis. In this study, we used PCA to establish an evaluation system for physio-biochemical indexes (e.g. decay rate, weight loss, peel colour, nutrients contents, respiratory intensity, relative electrical conductivity (REC), hydrogen peroxide $\left(\mathrm{H}_{2} \mathrm{O}_{2}\right)$ and MDA contents, and antioxidant enzyme activities) related to treatments at different storage temperatures, which could be used as a basis for comprehensively evaluating Ponkan mandarins storage and preservation under different storage temperatures. The suitable storage temperatures of Ponkan mandarins were determined, providing a theoretical basis for actual postharvest management to reduce losses and thereby help increase profit.

\section{MATERIALS AND METHODS}

\section{Ponkan mandarins and storage conditions}

Fresh Ponkan mandarins grafted on rootstock trifoliate orange were harvested 195 days after full-bloom (DAF) stage with a ratio of TSS/TA $>10$ from a 16-year-old commercial orchard with the integrated management of water and fertiliser in the Xiangtian district of Jing'an City $\left(28^{\circ} 48^{\prime} 47^{\prime \prime} \mathrm{N}\right.$ and $115^{\circ} 23^{\prime} 59^{\prime \prime}$ E, Jiangxi Province, China), in November 2018, and transported back to the Jiangxi provincial key laboratory of fruit and vegetable preservation and nondestructive testing (Nanchang, Jiangxi, China) within $4 \mathrm{~h}$. After pre-storage for 3 days, the healthy fruits without diseases or mechanical damage and uniform in colour, size, shape and maturity were selected. Then, 1,800 fruits were randomly separated into four lots, and stored at $5 \pm 1{ }^{\circ} \mathrm{C}(\mathrm{S} 5), 10 \pm 1{ }^{\circ} \mathrm{C}(\mathrm{S} 10)$, $15 \pm 1{ }^{\circ} \mathrm{C}(\mathrm{S} 15)$ and $20 \pm 1{ }^{\circ} \mathrm{C}$ (Control) with a relative humidity of $85-90 \%$ for 120 days. We selected 15 fruits from each temperature lot every 15 days to evaluate their physiological and biochemical indexes.

\section{Evaluation of decay rate and weight loss}

The decay rate (DR) of Ponkan mandarins showing obvious symptoms of fungal disease was measured on the same 300 fruits of three replicates in each lot, and calculated on the initial fruit number for each lot every 15 days, and is expressed in percentage.

The weight loss (WL) of Ponkan mandarins was measured on the same 30 fruits of three replicates in each lot, and calculated on the initial fruit weight basis for each lot every 15 days, and is expressed in percentage of the initial weight. 


\section{Measurement of fruit colour}

The light ( $\left.\mathrm{L}^{*}\right)$ value and citrus colour index (CCI) were measured using a MINOLTA CR-400 colorimeter (D65 light source; Konica Minolta Sensing, Inc., Osaka, Japan) for 15 fruits randomly from three replicates in each temperature lot, following the method of Rapisarda et al. (2001).

\section{Fruit quality analysis}

About $10.0 \mathrm{~g}$ of fruit pulp from five fruits per replicate in each temperature lot was homogenised and centrifuged at 7,500 $\times \mathrm{g}$ for $15 \mathrm{~min}$. The supernatant was obtained and used for measuring TSS content with the aid of a RA250WE Brix-meter (Atago, Tokyo, Japan), and the result is expressed as ${ }^{\circ} \mathrm{Brix}$. Both contents of TA and VC were determined by titration with $0.1 \mathrm{M}$ sodium hydroxide (Chen et al., 2016) and 2,6-dichlorophenolindophenol (Rapisarda et al., 2001), which were expressed as a percentage of citric acid and $\mathrm{mg} \cdot 100 \mathrm{~g}^{-1}$, respectively. Both total phenol content (TPC) and total flavonoid content (TFC) were assayed based on the methods reported by Nie et al. (2020) using gallic acid (GA) and rutin as the standard, where the TPC and TFC were expressed as $\mathrm{mg} \cdot \mathrm{g}^{-1}$ on the basis of frozen weight.

\section{Assay of respiration intensity (RI)}

Fruit RI was measured using a GXH-3051H infrared carbon dioxide fruit and vegetable respiration tester (Jun-Fang-Li-Hua Technology-Research Institute Beijing, China) in units of $\mathrm{mg} \mathrm{CO}_{2} \cdot \mathrm{kg}^{-1} \cdot \mathrm{h}^{-1}$. We selected randomly five fruits per replicate in each temperature lot for measurement after weighting.

\section{Lipid peroxidation levels assays}

\section{Relative electrical conductivity}

To estimate the membrane stability, the REC was determined using the method of Ning et al. (2019). $2.0 \mathrm{~g}$ of peel samples from five fruits was excised with a $10-\mathrm{mm}$-diameter puncher, and rinsed in $20 \mathrm{~mL}$ of distilled water. After shaking at $25^{\circ} \mathrm{C}$ for $20 \mathrm{~min}$, the initial conductivity $\left(\mathrm{P}_{0}\right)$ was measured by a conductivity metre (DDS-307A; Rex Shanghai, China). The samples were then heated to $100{ }^{\circ} \mathrm{C}$ for $20 \mathrm{~min}$ and quickly cooled down to $25^{\circ} \mathrm{C}$, and the final electrical conductivity $\left(\mathrm{P}_{1}\right)$ was taken. The REC (\%) was calculated following the formula: $\mathrm{P}_{0} / \mathrm{P}_{1} \times 100$.

\section{Hydrogen peroxide content}

The $\mathrm{H}_{2} \mathrm{O}_{2}$ content was assayed by an $\mathrm{H}_{2} \mathrm{O}_{2}$ test kit (No: A064-1-1; Nanjing Jiancheng Bioengineering Institute, Nanjing, China) with the molybdate colorimetric method. The result was expressed as millimoles per gram $\left(\mathrm{mmol} \cdot \mathrm{g}^{-1}\right)$ of pericarp-frozen-weight $(\mathrm{FW})$.

\section{MDA content}

Membrane lipid peroxidation was estimated by MDA content. 5.0 g peel samples from five fruits were used to determine the MDA content referring to the method described in our previous studies (Chen et al., 2019; Wan et al., 2020). The grounded samples were homogenised in $25 \mathrm{~mL}$ of ice-cold $50 \mathrm{mM}$ phosphate buffer ( $\mathrm{pH} \quad 7.5$; containing 2\% $(w / v)$ polyvinylpyrrolidone) and then centrifuged at $12,000 \times g$ for $20 \mathrm{~min}$. $2 \mathrm{~mL}$ of the supernatant was mixed with equal amounts of $0.5 \%$ thiobarbituricacid (TBA, prepared in $50 \mathrm{mM}$ phosphate buffer). After being boiled for $15 \mathrm{~min}$, the absorbance of these mixtures was recorded at $450 \mathrm{~nm}, 532 \mathrm{~nm}$ and $600 \mathrm{~nm}$. The results were expressed as millimoles per gram $\left(\mathrm{mmol} \cdot \mathrm{g}^{-1}\right)$ of pericarp-FW.

\section{Determination of antioxidant enzymes activities}

\section{SOD; EC 1.15.1.1 activity}

The SOD activity was measured using a SOD test kit (No: A001-1-2; Nanjing Jiancheng Bioengineering Institute, Nanjing, China) with the hydroxylamine method. The absorbance of the tested sample was monitored at $550 \mathrm{~nm}$. One unit of SOD activity was determined to inhibit $50 \%$ of nitroblue tetrazolium (NBT) photoreduction per minute. The assay of SOD activity was performed in triplicate.

\section{CAT; EC 1.11.1.6 activity}

The CAT activity was determined following the method of Nie et al. (2020). $0.5 \mathrm{~g}$ of peel sample was extracted with $5 \mathrm{~mL}$ of $100 \mathrm{mmol} \cdot \mathrm{L}^{-1}$ ice-cold phosphate buffer ( $\mathrm{pH} 7.5$; containing $5 \mathrm{mmol} \cdot \mathrm{L}^{-1}$ dithiothreitol and $5 \%$ polyvinylpyrrolid) and then centrifuged at $4{ }^{\circ} \mathrm{C}$ at $12,000 \times g$ for $15 \mathrm{~min}$. The reaction system for measuring CAT activity consisted of $80 \mu \mathrm{L}$ of supernatant and $2.9 \mathrm{~mL}$ of $20 \mathrm{mmol} \cdot \mathrm{L}^{-1} \mathrm{H}_{2} \mathrm{O}_{2}$ (prepared in $100 \mathrm{mmol} \cdot \mathrm{L}^{-1}$ phosphate extraction buffer). The decomposition of $\mathrm{H}_{2} \mathrm{O}_{2}$ was determined at $240 \mathrm{~nm}$ for $3 \mathrm{~min}$. One unit of CAT activity was defined as the decline of 0.01 in absorbance per minute, and expressed as $\mathrm{U} \cdot \mathrm{min}^{-1} \cdot \mathrm{g}^{-1}$. The assay of CAT activity was performed in triplicate.

\section{POD; EC 1.11.1.7 activity}

The POD activity was assayed using the guaiacol method reported by previous studies (Chen et al., 2020; Moosa et al., 2019). $0.5 \mathrm{~g}$ of frozen peel sample was extracted with $5 \mathrm{~mL}$ of $100 \mathrm{mmol} \cdot \mathrm{L}^{-1}$ ice-cold acetate buffer ( $\mathrm{pH} 5.5$; containing $1 \%$ Triton $\mathrm{X}-100,1 \mathrm{mmol} \cdot \mathrm{L}^{-1}$ polyethylene glycol, $4 \%$ polyvinylpyrrolidone and then centrifuged at $12,000 \times g$ for $30 \mathrm{~min}$ at $4{ }^{\circ} \mathrm{C}$. $50 \mu \mathrm{L}$ of the obtained supernatant was mixed with $200 \mu \mathrm{L}$ of $0.5 \mathrm{mM}$ $\mathrm{H}_{2} \mathrm{O}_{2}$ and $3.0 \mathrm{~mL}$ of $25 \mathrm{mmol} \cdot \mathrm{L}^{-1}$ guaiacol (prepared in $100 \mathrm{mmol} \cdot \mathrm{L}^{-1}$ acetate buffer) The oxidation of guaiacol was determined at $470 \mathrm{~nm}$ for $5 \mathrm{~min}$. One unit of POD activity was defined as the increase of 0.01 in absorbance per minute, and expressed as $\mathrm{U} \cdot \mathrm{min}^{-1} \cdot \mathrm{g}^{-1}$. The assay of POD activity was performed in triplicate.

\section{APX; EC1.11.1.11 activity}

The APX activity was measured following the method of Halka et al. (2019). $0.5 \mathrm{~g}$ of peel sample was mixed 
with $5 \mathrm{~mL}$ of $100 \mathrm{mmol} \cdot \mathrm{L}^{-1}$ ice-cold phosphate buffer (containing $0.1 \mathrm{mmol} \cdot \mathrm{L}^{-1}$ ethylene diamine tetraacetic acid, $0.5 \mathrm{mmol} \cdot \mathrm{L}^{-1}$ ascorbic acid, and $2 \%$ polyvinylpyrrolidone) and then centrifuged at $12,000 \times g$ for $30 \mathrm{~min}$ at $4{ }^{\circ} \mathrm{C} .80 \mu \mathrm{L}$ of the supernatant was mixed with $2.6 \mathrm{~mL}$ of $50 \mathrm{mmol} \cdot \mathrm{L}^{-1}$ phosphate buffer (containing $0.5 \mathrm{mmol} \cdot \mathrm{L}^{-1}$ ascorbic acid and $0.1 \mathrm{mmol} \cdot \mathrm{L}^{-1}$ ethylene diamine tetraacetic acid) and $0.3 \mathrm{~mL}$ of $2 \mathrm{mmol} \cdot \mathrm{L}^{-1} \mathrm{H}_{2} \mathrm{O}_{2}$. APX activity was expressed as $\mathrm{U} \cdot \mathrm{min}^{-1} \cdot \mathrm{g}^{-1}$, where one unit was defined as the decrease rate of absorbency at $290 \mathrm{~nm}$ per min. The assay of APX activity was performed in triplicate.

\section{Data analysis}

All experiments were performed in triplicate. All data were presented as means \pm standard deviation (SD) with $n=3$, and analysed by the Duncan's multiple range test at a significance level of $0.05(p<0.05)$ using SPSS 22.0 software (IBM SPSS 22.0, Chicago, IL, USA).

\section{RESULTS AND DISCUSSION}

\section{Effects of different storage temperatures on $D R, W L, L *$ and $C C I$}

The DR and WL rate are important indexes for evaluating the storability of citrus fruit (Montero et al., 2009). Figure $1 \mathrm{~A}$ illustrates the DR in all groups was kept to zero during the first 30 days of storage. The rotten fruit appeared in S5, S10, S15 treated, and control groups on the 45th day of storage. At the end of storage (120 days), the DR of S5 and S10-treated fruits were $40.2 \%$ and $52.1 \%$ lower than that of S20-treated fruits, respectively. We found significant differences between all groups $(p<0.05)$. Numerous previous studies have reported that low-temperature storage slows the DR of citrus (Henriod et al., 2005). Low-temperature storage may reduce the occurrence of fruit diseases and insect pests (Tietel et al., 2012).

Due to both water transpiration and nutrients degradation by respiration, the WL of all groups increased with the prolongation of storage. As shown in Figure $1 \mathrm{~B}$, the storage temperature at $5{ }^{\circ} \mathrm{C}$ and $10{ }^{\circ} \mathrm{C}$ could significantly reduce the WL of Ponkan mandarins $(p<0.05)$. At the end of storage, the lowest WL was $4.19 \%$ and was found in S5-treated fruit, which is $37.2 \%$ lower than that of the S20-treated (control) fruit. Some studies reported that, low-temperature storage can reduce fruit WL (Undurraga et al., 2009; Tietel et al., 2012), which may be due to the slow water transpiration and fruit respiration caused by low temperature, offering a relatively high humidity environment and maintaining the moisture and nutrients contents of fruits.

Low-temperature storage at a suitable temperature is beneficial for maintaining the appearance, colour and exterior quality of fruits, improving the storability, and prolonging the shelf life (Hong et al., 2013; Lado et al., 2018; Matsumoto et al., 2019). To some extent, the fruit colour reflects the freshness and postharvest quality of horticultural products. The $\mathrm{L}^{*}$ value decreased slightly with the prolongation of storage time (Figure 1C). During
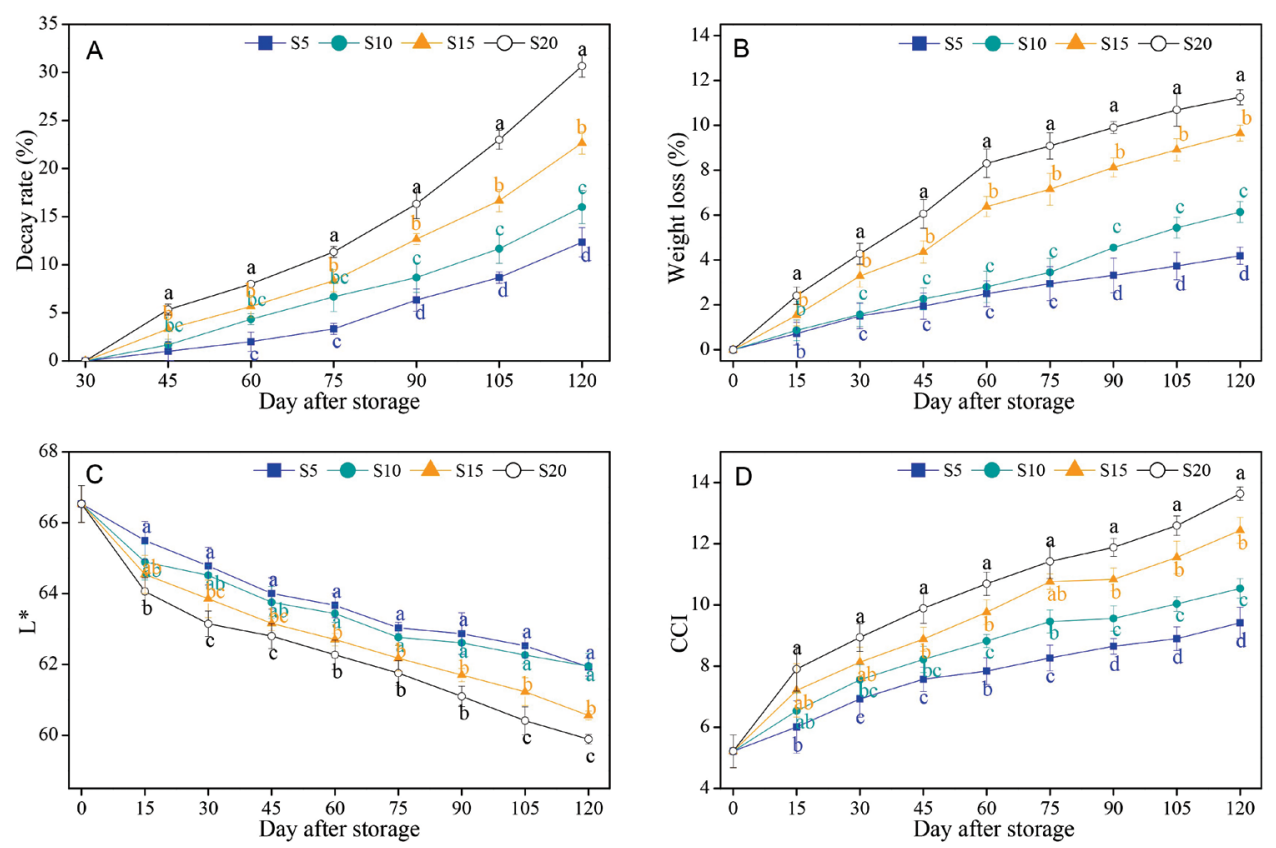

Figure 1. (A) Effect of different storage temperatures on decay rate, (B) weight loss, (C) L* value and (D) CCI of Ponkan mandarins. Data represent the mean $\pm \operatorname{SD}(n=3)$. The columns with different lowercase letters $(\mathrm{a}, \mathrm{b}, \mathrm{c}$ and $\mathrm{d})$ among different treatments within the same time point are significantly different according to the Duncan's test at $p<0.05$. CCI, citrus colour index; SD, standard deviation. 
the whole storage period, the $\mathrm{L}^{*}$ value was significantly lower $(p<0.05)$ in S15 and S20 treated fruit compared with the S5 and S10 treated fruit. The CCI of Ponkan mandarins stored at different temperatures increased gradually with the increase in storage time (Figure 1D). However, under low-temperature storage, the increment of CCI in S5 and S10 treated fruit was significantly slower $(p<0.05)$ than that in S15 treated and control fruit. In this experiment, Ponkan mandarins maintained good appearance and lustre after long storage at $5{ }^{\circ} \mathrm{C}$ and $10{ }^{\circ} \mathrm{C}$. These results are highly consistent with those reported in other studies (Matsumoto et al., 2009; Nawaz et al., 2020). Storage temperature affects the colour development and appearance quality trait in citrus fruit, thus significantly affecting its exterior quality. Ponkan mandarins stored at $10{ }^{\circ} \mathrm{C}$ have a better appearance, brighter $\mathrm{L}^{*}$ value, lower CCI and more sluggish fruit senescence. These results also indicate that too low storage temperature $\left(5^{\circ} \mathrm{C}\right)$ is not conducive for fruit colouration and after-ripening.

\section{Effects of different storage temperatures on TSS, $T A$ and $V C$}

The TSS, TA and VC contents are important factors for assessing the nutritional quality and flavour of citrus fruits (Lado et al., 2018; Chen et al., 2019). TSS in citrus juice is composed of acid soluble pectins, vitamins, sugars and some soluble proteins (Alhassan et al., 2019). The TSS content of fruits stored at different temperatures increased first to achieve their peaks, followed by a decline in TSS content during the remainder of the storage period. The peak of TSS content in each treatment group differed, and then the TSS content of each treated fruit decreased rapidly (Table 1A). The TSS content of S10-treated fruit was significantly higher $(p<0.05)$ than the other three treatments during the mid-late-storage periods (60-120 days). Similar results were reported by Alhassan et al. (2019) for Afourer mandarins and navel oranges.

The TA content is regarded as an important index for evaluating fruit flavour and RR of horticultural crops (Bal, 2013; Chen et al., 2019). In our study, during storage, the TA content in all groups decreased continuously with the increase of storage time, with the control group undergoing the fastest degradation of TA. At the end of storage (120 days), the TA content in S5, S10, S15 and S20-treated groups were $0.63 \%$, $0.61 \%, 0.38 \%$ and $0.33 \%$, respectively (Table $1 \mathrm{~B}$ ). The TA content of S5 and S10-treated fruit retained the initial level of $38.7 \%$ and $37.4 \%$, whereas only $20.2 \%$ was retained in the S20-treated fruit. In this study, the high TA content in the S10-treated fruit may be due to the lower RR, which delayed the degradation of TA (Tietel et al., 2012; Alhassan et al., 2019).

Vitamin $\mathrm{C}$ is one of the key factors used to evaluate the quality of mandarin fruit. As shown in Table 1C, the VC content of fruits stored at different temperatures first increased and then decreased in the subsequent storage period. The peak times of $\mathrm{VC}$ content in each treatment group differed (e.g. 15 days in both S15 and S20 groups and 30 days in both S5 and S10 groups). The VC content in the S10-treated fruit was significantly higher than the other three treatments after the 15th day of storage $(p<0.05)$. These results are similar to those reported by Baltazari et al. (2020); the storage temperature was found to be an important factor affecting the nutritional quality of citrus. Therefore, determining the best minimum safe storage temperature for each citrus variety is important.

\section{Effects of different storage temperatures on TPC and TFC}

Phenols and flavonoids are important secondary metabolites in plants. Most of them have the capacity to scavenge free radicals and play an important role in the plant defence mechanism (Nie et al., 2020; Piljac-Zegarac and Samec, 2011). Both contents of total phenols and flavonoids in Ponkan mandarins increased first, and then decreased during the remainder of storage (Table 1). The TPC reached a peak at $45 \mathrm{~d}$ and then decreased (Table 1D). The decrease in TPC in S10-treated fruit was significantly lower than that of the other three treatments after the 45th day of storage $(p<0.05)$. The changes in TFC were likely similar to that of TPC, reaching the peak at the 60th day of storage and then decreasing in the subsequent storage period. The TFC in S10-treated fruit was 1.49 times higher than that at the beginning of storage (Table 1E), and was significantly $(p<0.05)$ different from that of the other three treatments. In this study, high TPC and TFC were maintained in S10-treated fruit (Table 1), consistent with a previous report that lowtemperature storage can maintain high anthocyanins content in blood orange (Rapisarda et al., 2001). In this study, the results indicated that the appropriate storage temperature could improve the oxidation resistance of fruits by increasing the secondary metabolites with defensive ability in fruit tissues.

\section{Effects of different storage temperatures on RI, $\mathrm{REC}, \mathrm{H}_{2} \mathrm{O}_{2}$ content and MDA content}

The RR of Ponkan mandarins increased under different temperature treatments (Figure 2A). Low-temperature storage significantly slowed the increase in the RI of Ponkan mandarins, and a significant difference $(p<0.05)$ in both $\mathrm{S} 5$ and S10-treated groups was found between the earlier and later stage of storage compared with the S15 and S20-treated groups $(p<0.05)$. Similar results were reported by Koh et al. (1998) for Satsuma mandarin storage; the RI of Satsuma mandarin fruit storage at $10{ }^{\circ} \mathrm{C}$ was significantly lower than that at the other three temperatures $\left(4{ }^{\circ} \mathrm{C}, 20^{\circ} \mathrm{C}\right.$ and $\left.35^{\circ} \mathrm{C}\right)$ treatments. This is analogous to low-temperature storage, which can reduce fruit respiration of Ponkan mandarins during storage.

The level in REC of Ponkan mandarins increased irrespective of storage temperature (Figure 2B), because the gradual senescence of fruits during storage may lead to increased permeability of the pericarp cell 


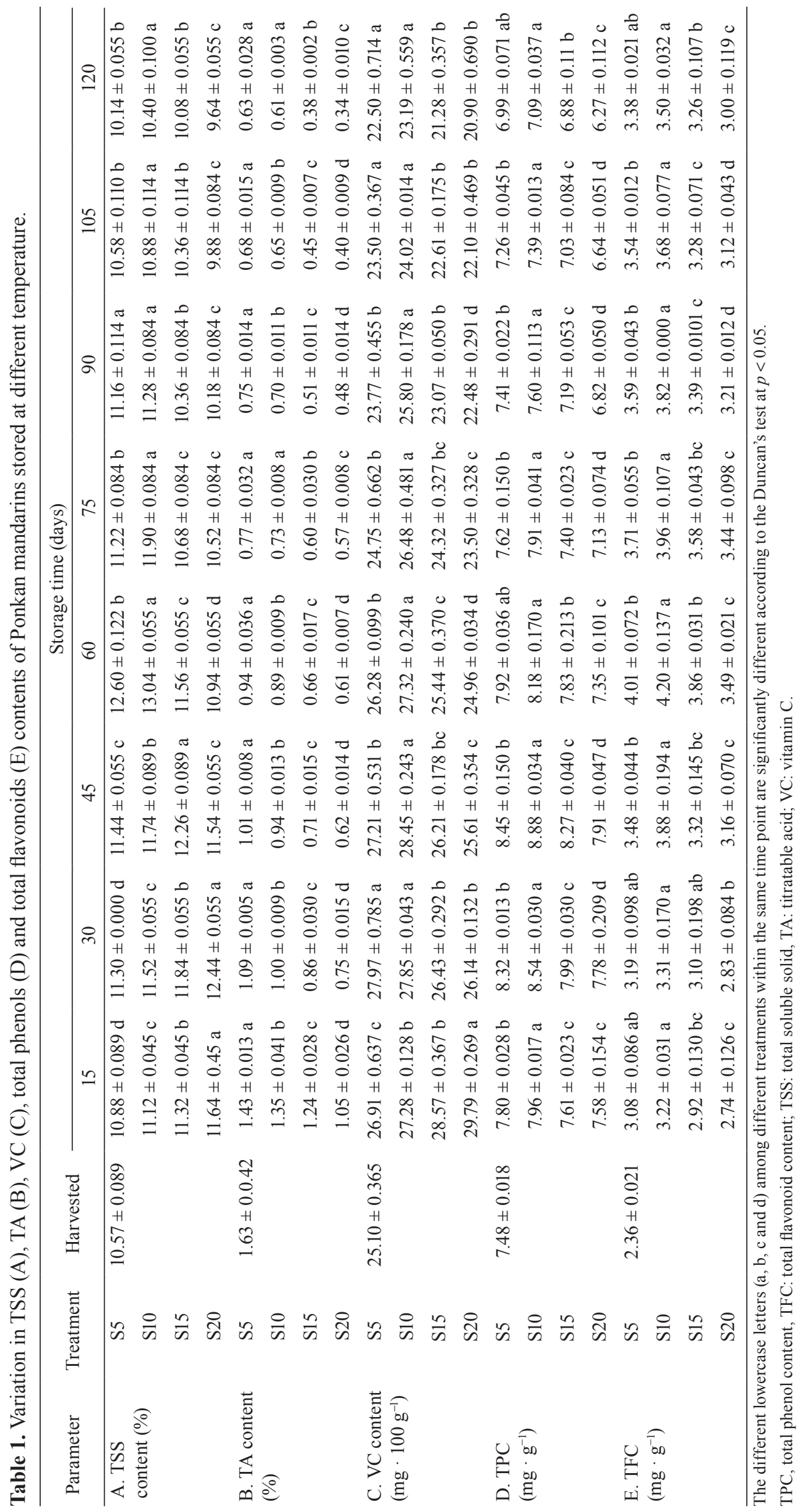



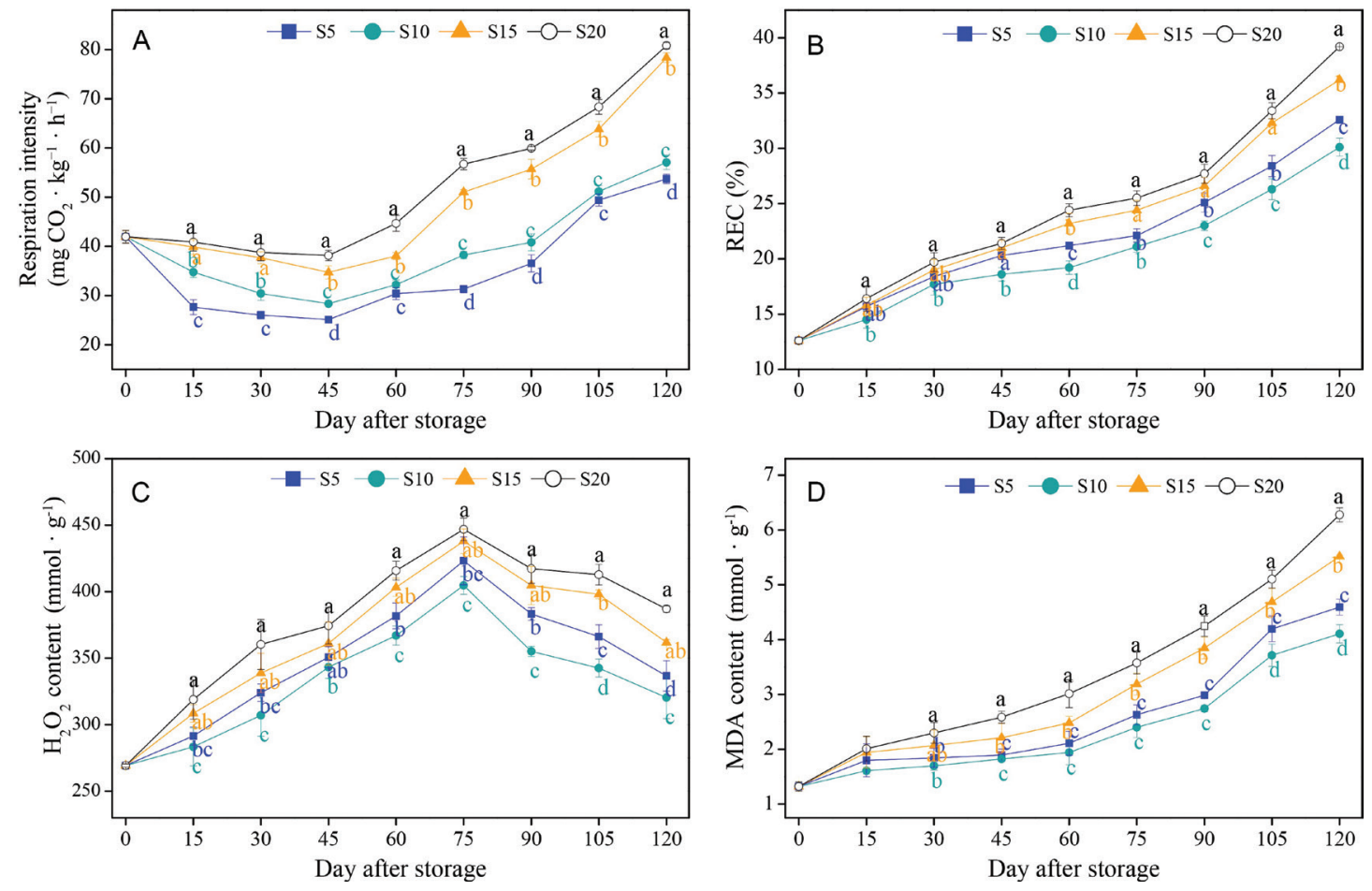

Figure 2. (A) Effect of different storage temperature on RI, (B) REC, (C) $\mathrm{H}_{2} \mathrm{O}_{2}$ content, and (D) MDA content of Ponkan mandarins. Data represent the mean $\pm \mathrm{SD}(n=3)$. The columns with different lowercase letters $(\mathrm{a}, \mathrm{b}, \mathrm{c}$ and $\mathrm{d})$ among different treatments within the same time point are significantly different according to the Duncan's test at $p<0.05$. MDA, malondialdehyde; RI, respiration intensity; REC: relative electrical conductivity; SD, standard deviation.

membranes. After storage for 120 days, the REC was $32.6 \%$ in S5-treated fruit, and 30.1\% in S10-treated fruit, $36.2 \%$ in S15-treated fruit and $39.2 \%$ in S20-treated fruit, respectively. The REC in S10-treated fruit was significantly lower $(p<0.05)$ than in the other three treatments, suggesting that too low storage temperature might lead to chilling damage, and high storage temperature may accelerate the nutrients degradation and fruit senescence.

Hydrogen peroxide is one of the important representatives of reactive oxygen species (ROS), and its accumulation causes fruit senescence (Mittler, 2002). The extension of storage time promoted the $\mathrm{H}_{2} \mathrm{O}_{2}$ accumulation; after the peak of $\mathrm{H}_{2} \mathrm{O}_{2}$ content at 75 days of postharvest storage, it rapidly decreased (Figure 2C). In comparison with the other three treatments, the $\mathrm{H}_{2} \mathrm{O}_{2}$ content slowly increased and then quickly decreased, suggesting that low-storage temperature inhibits the $\mathrm{H}_{2} \mathrm{O}_{2}$ accumulation and exhibited a lower level of $\mathrm{H}_{2} \mathrm{O}_{2}$ content, compared with that observed in those fruits stored at too low and high storage temperature (S5, S15 and $\mathrm{S} 20$ groups; $p<0.05$ ). In this study, low-temperature storage delayed fruit senescence, resulting in a reduction in the accumulation of $\mathrm{H}_{2} \mathrm{O}_{2}$.

The damage of oxidative stress increased during storage, and excess ROS increased the MDA accumulation and destroyed cell membrane structure, thereby accelerating fruit senescence (Chen et al., 2019; Mittler, 2002). Membrane lipid peroxidation was expressed as MDA content (the final decomposing product of membrane lipid peroxidation), which is closely related to ageing and is one of the direct indicators of membrane oxidative damage. Figure 2D shows that the MDA content in each treatment presented an escalating tendency as the storage time increased. Fruit stored at $10{ }^{\circ} \mathrm{C}$ had the lowest MDA content compared with the other three treatments after storage ( $p<0.05$; Figure 2D). Therefore, the accumulation of MDA may be related to the senescence and high VC content of fruits stored at low temperature. To further understand the reason for this change, the future analysis protective enzyme activity that delays lipid peroxidation and cell ageing is needed.

\section{Effects of different storage temperatures on antioxidant enzyme activities}

The activities of SOD, CAT, POD and APX are closely related to antioxidation and anti-ageing in plant tissues (Rao et al., 2011; Nie et al., 2020). During the entire storage period, these enzyme activities in Ponkan mandarins initially increased and then notably decreased (Figure 3). As revealed in Figure 3A, the SOD activity in control, S15, S10 and S5-treated fruit reached their highest levels at 45 days and 60 days, indicating that low storage temperature can effectively improve SOD activity and retard the peak time during the storage time. The higher level of SOD activity was noticed in S10-treated fruit compared with the other 

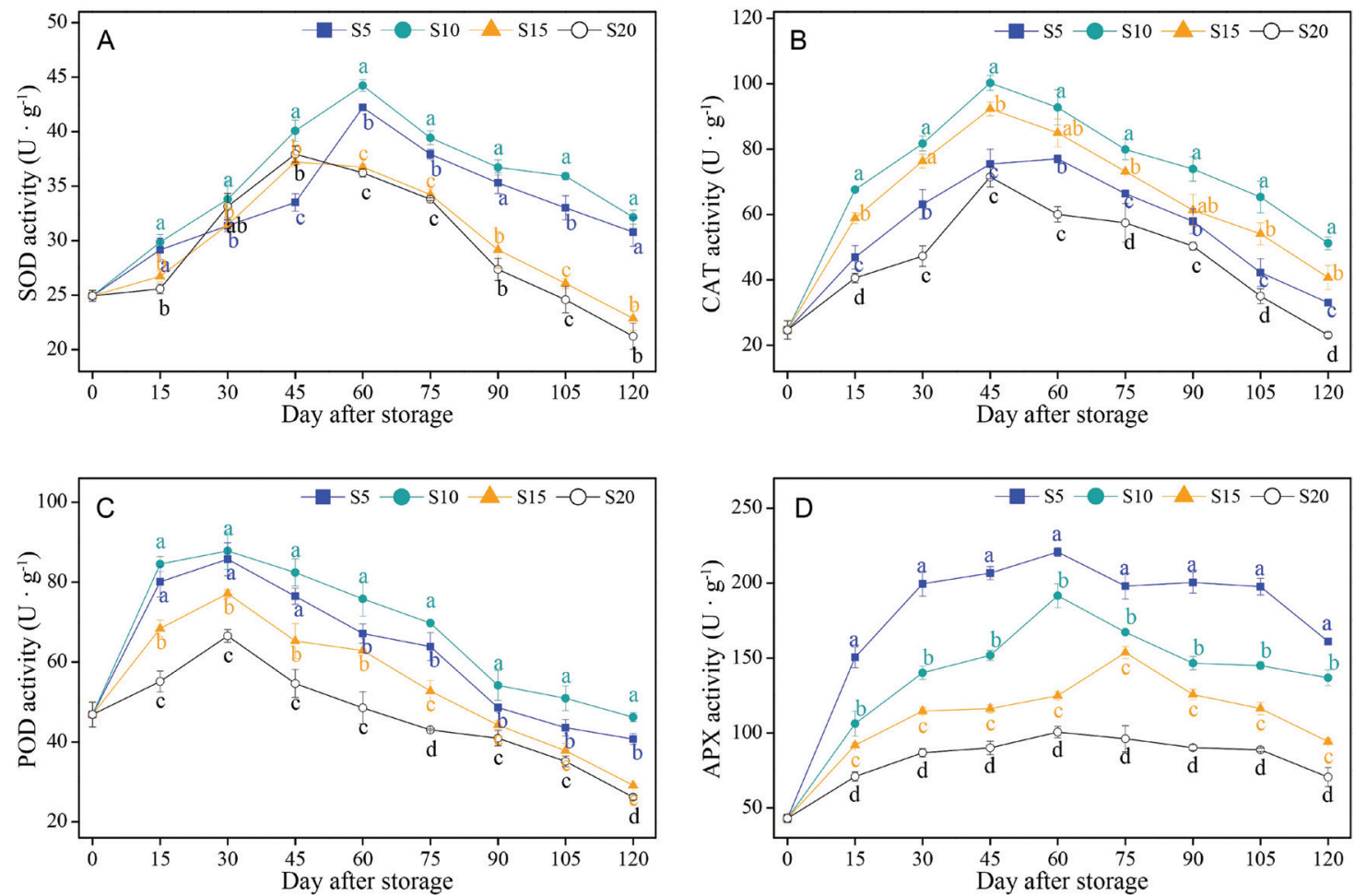

Figure 3. (A) Effect of different storage temperatures on SOD activity, (B) CAT activity, (C) POD activity and (D) APX activity of Ponkan mandarins. Data represent the mean $\pm \operatorname{SD}(n=3)$. The columns with different lowercase letters ( $\mathrm{a}, \mathrm{b}, \mathrm{c}$ and $\mathrm{d}$ ) among different treatments within the same time point are significantly different according to the Duncan's test at $p<0.05$. APX, ascorbate peroxidase; CAT, catalase; POD, peroxidase; SD, standard deviation; SOD, superoxide dismutase.

three treatments (S5, S15 and S20) at various sampling times $(p<0.05$; Figure 3A). The CAT activity levels in S10-treated fruit reached a maximum value on the 45 th day, exhibiting values that were $32.89 \%, 8.56 \%$ and $40.14 \%$ higher relative to its levels in S5, S15 and S20 fruit, respectively (Figure 3B). The POD activity peaked at 30 days and then decreased rapidly (Figure 3C). The decline of POD activity in S10-treated fruit was significantly slower $(p<0.05)$ than the S5, S15 and S20 groups. A significantly elevated APX level was observed in Ponkan mandarins exposed to low temperature compared with the S20-treated fruit throughout the storage (Figure 3D). From an initial storage ( 0 days) to the end storage, the increase in APX activity in S5, S10 and S15-treated fruit was on average $114.1 \%, 66.68 \%$ and $32.97 \%$ higher than that in the S20treated fruit, respectively $(p<0.05)$.

The excessive production and accumulation of ROS caused by fruit senescence destroys the integrity of the cell membrane and reduces the storage tolerance of fruit (Mittler, 2002; Undurraga et al., 2009). The high activity of antioxidant and defence-related enzymes can effectively reduce the accumulation of ROS and MDA, reduce oxidative damage, delay fruit ageing and prolong storage life. As important antioxidant enzymes, SOD and POD can prevent membrane lipid peroxidation caused by excessive ROS (Gill and Tuteja, 2010;
Rao et al., 2011). CAT plays an important part in the scavenging process of ROS. As a stress reaction, CAT usually changes with the change in ROS level. APX is the key enzyme for removing $\mathrm{H}_{2} \mathrm{O}_{2}$ in chloroplasts and the main enzyme for VC metabolism. In our study, the results indicated that low-temperature storage enhanced the activities of SOD, CAT, POD and APX, and lessened the accumulation of MDA (Figure 2 and 3). These results are consistent with those of Chen et al. (2019) and Zhang et al. (2011), compared with room temperature storage, where two citrus fruit varieties of Xinyu tangerines and 'Guanximiyou' pummelos stored at $6{ }^{\circ} \mathrm{C}$ exhibited the increase in antioxidant enzyme like SOD, CAT and POD activities, thereby inhibiting MDA accumulation and enhancing postharvest quality storage life.

\section{PCA for physicochemical indexes}

A PCA analysis was performed to assess the preservation efficacy of different storage temperatures on the postharvest quality of Ponkan mandarin by evaluating 17 physicochemical parameters. The eigenvalues of the covariance matrix suggested that the two principal components (PCs) are able to account for $87.233 \%$ of the total variance in the dataset, and PC1 was found to explain $58.195 \%$ and the PC2 explained an additional $29.038 \%$ of the variance (Figure $4 \mathrm{~A}$ ). 

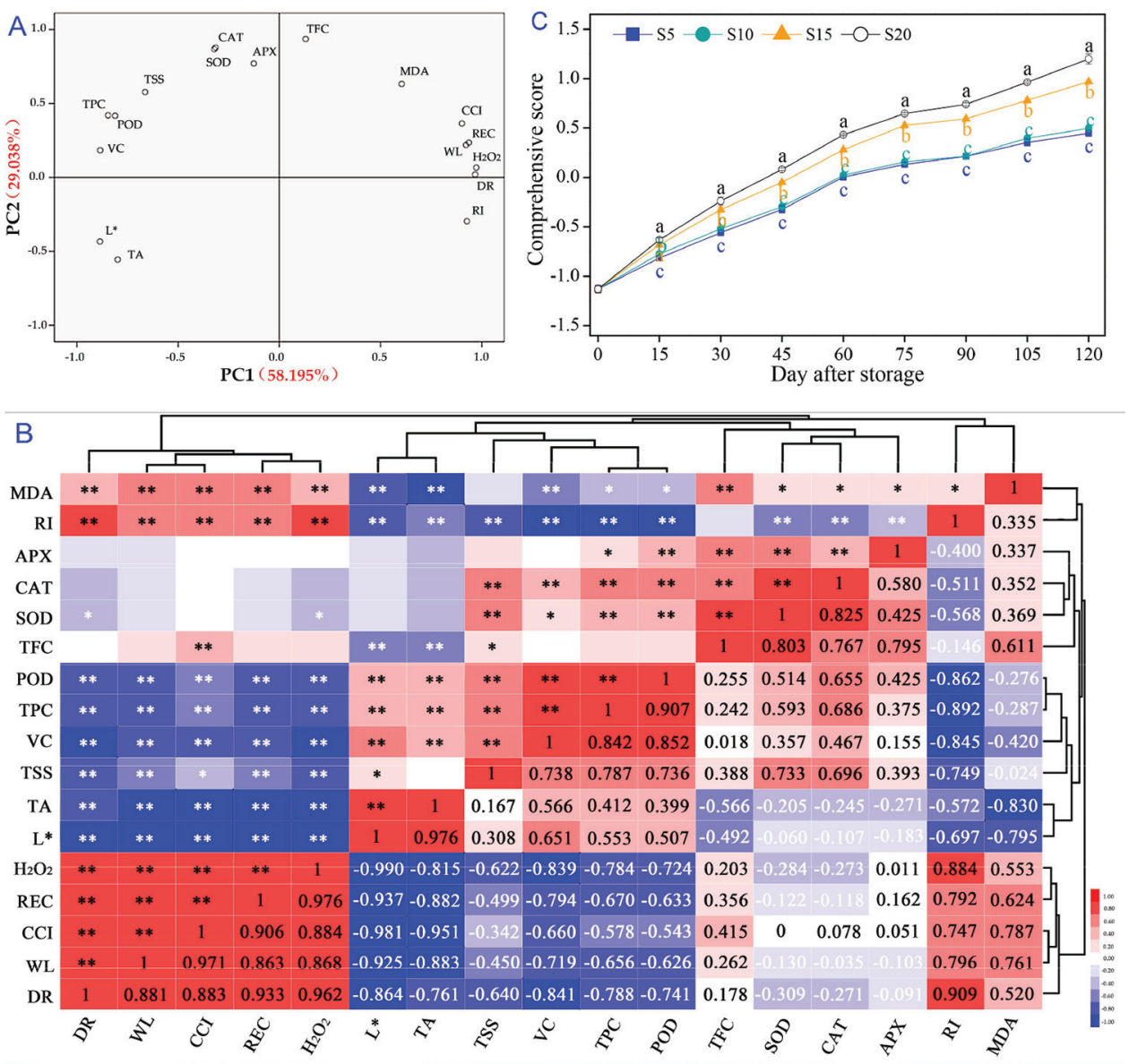

Figure 4. (A) Two-dimensional PCA, (B) cluster correlation heat map and (C) comprehensive score among 17 physicochemical quality indexes of Ponkan mandarin. APX, ascorbate peroxidase; CAT, catalase; CCI, citrus colour index; MDA, malondialdehyde; POD, peroxidase; PCA, principal component analysis; PC, principal components; REC, relative electrical conductivity; SOD, superoxide dismutase; TPC, total phenol content; VC, vitamin C.

The absolute value of the eigenvalues mirrored the contribution rate to each $\mathrm{PC}$, and the higher the absolute value, the greater the contribution rate. As illustrated in Figure 4B, both positive and negative correlations were intuitively observed among 17 postharvest physicochemical parameters. Interestingly, the seven positive axis of $\mathrm{PC} 1$ were decay rate, weight loss, CCI, REC, $\mathrm{H}_{2} \mathrm{O}_{2}$ content, $\mathrm{RI}$ and MDA content. Conversely, PC1 was negatively correlated with $\mathrm{L}^{*}$ value, POD activity and the contents of TSS, TA, VC (ascorbic acid) and total phenols. PC2 had high positive loading for TFC, SOD, CAT and APX activities (Figure 4B). Notably, the preservable index (e.g. decay rate and weight loss) of Ponkan mandarin was significantly positively correlated with CCI, RI, REC, $\mathrm{H}_{2} \mathrm{O}_{2}$ content and MDA content $(p<0.01)$, and negatively correlated with $\mathrm{L}^{*}$ value, the contents of TSS, TA, VC and total phenols, and POD activity $(p<0.01)$, respectively. Figure 4B shows that the comprehensive score of Ponkan mandarin increased gradually with storage time. Both the S5 and S10-treated fruit showed a lower increase in comprehensive score compared with the S20-treated and S15-treated fruit during the whole storage period. No significant difference was found in the comprehensive score between the S5 and
S10-treated fruit after the 30th day of storage until the end of storage (Figure 4C). The PCA results showed that Ponkan mandarin stored at $10^{\circ} \mathrm{C}$ exhibited better preservation effect compared with the control group. Postharvest low temperature storage treatment was effective to preserve Ponkan mandarin quality during the storage at $10{ }^{\circ} \mathrm{C}$. PCA is an effective way to evaluate the postharvest storability of different storage temperatures on Ponkan mandarin as reported by other studies in several citrus fruit, such as kumquat (Liu et al., 2018), 'Newhall' navel orange (Wan et al., 2020), and 'Majiayou' pummelo (Nie et al., 2020).

\section{CONCLUSIONS}

Our current study demonstrated that, Ponkan mandarins stored at $10^{\circ} \mathrm{C}$ for 120 days result in significantly better postharvest quality compared with those fruit stored at relatively high storage temperature (S15 and S20-treated groups), together with lower fruit DR, WL CCI, RI and $\mathrm{REC}$, as well as higher $\mathrm{L}^{*}$ value. Moreover, compared with the S5-treated fruit, the lower levels in REC, $\mathrm{H}_{2} \mathrm{O}_{2}$ and MDA accumulation in Ponkan mandarins stored at $10{ }^{\circ} \mathrm{C}$ might have been associated with high levels of scavenger antioxidant enzymes like SOD, CAT, POD 
and APX, thereby delaying fruit senescence process, maintaining high nutritional quality and prolonging the storage life.

\section{FUNDING}

This research was funded by 2011 Collaborative Innovation Center and Modern Agricultural Technology System of Citrus Industry in Jiangxi Province (Grant Numbers JXGS-05 and JXARS-07).

\section{AUTHOR CONTRIBUTIONS}

N.C. performed analysis, collected the data and wrote the original draft. C.W. helped to write the manuscript and perform the formal analysis. J.C. provided financial support and an experimental platform. C.C. developed the concept, and planned and designed the experimental layout.

\section{CONFLICT OF INTEREST}

The authors declare no conflict of interest.

\section{REFERENCES}

Alhassan, N., Golding, J. B., Wills, R. B. H., Bowyer, M. C., And PRistijono, P. (2019). Long term exposure to low ethylene and storage temperatures delays calyx senescence and maintains 'Afourer' mandarins and navel oranges quality. Foods, 8, 19, doi: 10.3390/ foods 8010019 .

BAL, E. (2013). Postharvest application of chitosan and low temperature storage affect respiration rate and quality of plum fruits. Journal of Agriculture, Science and Technology, 15, 1219-1230.

Baltazari, A., Mtui, H. D., Mwatawala, M. W., Chove, L. M., Msogoya, T., Samwel, J., and Subramanian, J. (2020). Effects of storage conditions, storage duration and post-harvest treatments on nutritional and sensory quality of orange (Citrus sinensis L. Osbeck) fruits. International Journal of Fruit Science, 20, 737-749.

Carvajal, F., Martinez, C., Jamilena, M., and Garrido, D. (2011). Differential response of zucchini varieties to low storage temperature. Scientia Horticulturae, 130, 90-96.

Chaluta, E., Waks, J., and Schiffmann-Nadel, M. (1985). A comparison of the response of different citrus fruit cultivars to storage temperature. Scientia Horticulturae, 25, 271-277.

Chaudhary, P. R., Yu, X., Jayaprakasha, G. K., and PAtil, B. S. (2017). Influence of storage temperature and low-temperature conditioning on the levels of health-promoting compounds in Rio Red grapefruit. Food Science \& Nutrition, 5, 545-553.

Chen, C. Y., Peng, X., Zeng, R., Chen, M., Wan, C. P., and Chen, J. Y. (2016). Ficus hirta fruits extract incorporated into an alginate-based edible coating for Nanfeng mandarin preservation. Scientia Horticulturae, 202, 41-48.

Chen, C. Y., Wan, C. P., Jian, H. Z., Zou, Z. Q., Zeng, T., AND Chen, J. Y. (2019). Effects of different cold storage temperature on postharvest quality of Xinyu tangerines. Molecular Plant Breeding, 17, 2019-2024.

Chen, C. Y., Wan, C. P., Peng, X., And Chen, J. Y. (2020). A flavonone pinocembroside inhibits Penicillium italicum growth and blue mold development in 'Newhall' navel oranges by targeting membrane damage mechanism. Pesticide Biochemistry and Physiology, 165, 104505.

Cronje, P. J. R., Barry, G. H., And Huysamer, M. (2011). Postharvest rind breakdown of 'Nules Clementine' mandarin is influenced by ethylene application, storage temperature and storage duration. Postharvest Biology and Technology, 60, 192-201.

Ding, C. K., Chachin, K., Hamauzu, Y., Ueda, Y., and IMAHORI, Y. (1998). Effects of storage temperatures on physiology and quality of loquat fruit. Postharvest Biology and Technology, 14, 309-315.

Gao, Y., Kan, C. N., Chen, M., Chen, C. Y., Chen, Y. H., Fu, Y. Q., WAN C. P., AND Chen, J. Y. (2018). Effects of chitosan-based coatings enriched with cinnamaldehyde on mandarin fruit $\mathrm{cv}$. Ponkan during room-temperature storage. Coatings, 8, 372-384.

Gill, S. S., And Tuteja, N. (2010). Reactive oxygen species and antioxidant machinery in abiotic stress tolerance in crop plants. Plant Physiology and Biochemistry, 48, 909-930.

Halka, M., Smolen, S., Ledwozyw-Smolen, I., and SADY, W. (2019). Iodosalicylates and iodobenzoates supplied to tomato plants affect the antioxidative and sugar metabolism differently than potassium iodide. Folia Horticulturae, 31(2), 385-400.

Henriod, R. E., Gibberd, M. R., and Treeby, M. T. (2005). Storage temperature effects on moisture loss and the development of chilling injury in Lanes Late navel orange. Australian Journal of Experimental Agriculture, 45, 453-458.

Hong, K., Xu, H., Wang, J., Zhang, L., Hu, H., Jia, Z., Gu, H., He, Q., And Gong, D. (2013). Quality changes and internal browning developments of summer pineapple fruit during storage at different temperatures. Scientia Horticulturae, 151, 68-74.

Kan, C. N., GaO, Y., Wan, C. P., Chen, M., ZhaO, X., Liu, S., AND CHEN, J. Y. (2019). Influence of different cold storage times on quality of "Cuiguan" pear fruits during shelf life. Journal of Food Processing and Preservation, 43, e14245, doi: 10.1111/jfpp.14245.

KoH, J. S., Kim, W. T., LeE, S. Y., KIM, J. Y., AND KANG, C. H. (1998). Effects on the storage life of Satsuma mandarin by the pretreatment at various temperatures. Journal of Agricultural Chemistry and Biotechnology, 41, 228-233.

Lado, J., Gambetta, G., and Zacarias, L. (2018). Key determinants of citrus fruit quality: Metabolites 
and main changes during maturation. Scientia Horticulturae, 233, 238-248.

Liu, Y. M., Liu, Y., Liu, Y. M., Liu, H. D., And Shang, Y. S. (2018). Evaluating effects of ellagic acid on the quality of kumquat fruits during storage. Scientia Horticulturae, 227, 244-254.

Matsumoto, H., Adachi, Y., Ikoma, Y., and Kato, M. (2019). Effect of maturation stage and storage temperature and duration on beta-cryptoxanthin content in Satsuma mandarin (Citrus unshiu Marc.) fruit. The Horticulture Journal, 88, 214-221.

Matsumoto, H., Iкомa, Y., Kato, M., Nakajima, N., AND Hasegawa, Y. (2009). Effect of postharvest temperature and ethylene on carotenoid accumulation in the flavedo and juice sacs of Satsuma mandarin (Citrus unshiu Marc.) fruit. Journal of Agricultural and Food Chemistry, 57, 4724-4732.

Mittler, R. (2002). Oxidative stress, antioxidants and stress tolerance. Trends in Plant Science, 7, 405-410.

Montero, C. R. S., Schwarz, L. L., Santos, L. C. D., Andreazza, C. S., And Bender, R. J. (2009). Postharvest mechanical damage affects fruit quality of 'Montenegrina' and 'Rainha' tangerines. Pesquisa Agropecuária Brasileira, 44(12), 1636-1640.

Moosa, A., Sahi, S. T., Khan, S. A., and Malik, A. U. (2019). Salicylic acid and jasmonic acid can suppress green and blue moulds of citrus fruit and induce the activity of polyphenol oxidase and peroxidase. Folia Horticulturae, 31, 195-204. doi: 10.2478/ fhort-2019-0014.

Nawaz, R., Abbasi, N. A., Khan, M. R., Ali, I., Hasan, S. Z. U., AND Hayat, A. (2020). Color development in 'Feutrell's Early' (Citrus reticulata Blanco) affects peel composition and juice biochemical properties. International Journal of Fruit Science, 20, 871-890.

Nie, Z. P., Huang, Q., Chen, C. Y., Wan, C. P., And Chen, J. Y. (2020). Chitosan coating alleviates postharvest juice sac granulation by mitigating ROS accumulation in harvested pummelo (Citrus grandis L. Osbeck) during room temperature storage. Postharvest Biology and Technology, 169, 111309, doi: 10.1016/j.postharvbio.2020.111309.

Ning, M., Tang, F. X., Zhang, Q., Zhao, X. X., Yang, L. P., Caiai, W. C., And Shan, C. H. (2019). The quality of Gold Queen Hami melons stored under different temperatures. Scientia Horticulturae, 243, 140-147.

Piljac-Zegarac, J., and Samec, D. (2011). Antioxidant stability of small fruits in postharvest storage at room and refrigerator temperatures. Food Research International, 44, 345-350.

RaO, T. V. R., Gol, N. B., AND SHAh, K. K. (2011). Effect of postharvest treatments and storage temperatures on the quality and shelf life of sweet pepper (Capsicum annum L.). Scientia Horticulturae, 132, 18-26.

Rapisarda, P., Bellomo, S. E., And Intelisani, S. (2001). Storage temperature effects on blood orange fruit quality. Journal of Agricultural and Food Chemistry, 49, 3230-3235.

SALA, J. M. (1998). Involvement of oxidative stress in chilling injury in cold-stored mandarin fruits. Postharvest Biology and Technology, 13(3), 255-261.

Schirra, M. (1993). Behaviour of 'Star Ruby’ grapefruits under chilling and non-chilling storage temperature. Postharvest Biology and Technology, 2, 315-327.

TAng, D., Lin, Q., Liu, J., Wang, D., Liu, C., Wu, W., Sun, C., And Chen, K. (2017). Effects of combined heat and preservative treatment on storability of Ponkan fruit (Citrus reticulata Blanco cv. Ponkan) during postharvest storage. Journal of Food Quality, 7, 5871756, doi: 10.1155/2017/5871756.

Tietel, Z., Lewinsohn, E., Fallik, E., and Porat, R. (2012). Importance of storage temperatures in maintaining flavor and quality of mandarins. Postharvest Biology and Technology, 64, 175-182.

Undurraga, P. L., Olaeta, J. A., Retamales, J. B., Escobar, J., AND Toso, A. M. (2009). Effect of maturity and storage temperature on the development of peteca in lemons (Citrus limon (L.) Burm. F.) cv. Eureka. Scientia Horticulturae, 122, 56-61.

Wan, C. P., Kahramanoglu, İ., Chen, J. Y., Gan, Z. Y., AND CHen, C. Y. (2020). Effects of hot air treatments on postharvest storage of newhall navel orange. Plants, 9, 170, doi: 10.3390/plants9020170.

Wang, J. W., Jiang, Y. G., Li, G. D., Lv, M., Zhou, X., Zhou, Q., Fu, W. W., Zhang, L., Chen, Y. F., And JI, S. J. (2018). Effect of low temperature storage on energy and lipid metabolisms accompanying peel browning of 'Nanguo' pears during shelf life. Postharvest Biology and Technology, 139, $75-81$.

Zhang, X., ZhaO, Y., Pan, D., and Lin, H. (2011). Effects of storage temperatures on the quality and related enzymatic changes in Citrus guanxi-miyou fruit. Journal of Yunnan Agricultural University, 26, 348-353.

Zhu, A. D., Li, W. Y., Ye, J. L., Sun, X. H., Ding, Y. D., Cheng, Y. J., And Deng, X. X. (2011). Microarray expression profiling of postharvest Ponkan mandarin (Citrus reticulata) fruit under cold storage reveals regulatory gene candidates and implications on soluble sugars metabolism. Journal of Integrative Plant Biology, 53, 358-374.

Received: October 11, 2020; accepted: January 15, 2021 